\title{
Risk of Intracranial Aneurysms in Families With Subarachnoid Hemorrhage
}

\author{
Mark J. Alberts, Ana Quinones, Carmelo Graffagnino, Allan Friedman \\ and Allen D. Roses
}

\begin{abstract}
Background: Genetic factors may be important in the etiology of subarachnoid hemorrhage (SAH) and intracranial aneurysm (IA) formation. Several studies have reported the familial occurrence of SAH and IA, although in most cases asymptomatic family members were not studied with elective angiography. The examination of data from large sibships could provide important information about the frequency of IA occurrence in at-risk individuals and the mode of inheritance for familial SAH/IA. Methods: We reviewed published case series of sibships with SAH and at least four siblings, in which at least one sibling underwent elective angiography. Data were collected on age-of-onset, clinical events, presence of hypertension, angiographic findings, and outcome. Patients were classified as "affected" if they had a SAH or if an IA was detected by elective angiography, and "unaffected" if they were asymptomatic and had a negative angiogram. Results: Seven case series with 52 individuals (26 men and 26 women) met our inclusion criteria. The sibships ranged from 6 to 13 members. Most of the siblings ( 32 of $52,61 \%$ ) were asymptomatic, $18(35 \%)$ had a SAH, and $2(4 \%)$ had focal symptoms but no SAH. Elective angiography of 34 siblings showed an IA in $11(32 \%)$ and was negative in $23(68 \%)$. The overall rate of affecteds (SAH or IA) was $56 \%$. Conclusions: Based on data from these sibships, angiography of asymptomatic at-risk siblings demonstrated an IA in almost one-third of cases. Familial SAH/IA segregated with a pattern that was consistent with an autosomal dominant trait in this selected series of sibships, although other factors could produce these findings.
\end{abstract}

RÉSUMÉ: Risque d'anévrisme intracrânien dans la famille de patients ayant subi une hémorragie sous-arachnoïdienne. Introduction: Des facteurs génétiques sont probablement importants dans l'étiologie de l'hémorragie sousarachnoïdienne (HSA) et la formation de l'anévrisme intracrânien (AI). Plusieurs études ont rapporté le caractère familial de l'HSA et de l'AI, quoique dans la plupart de ces études une angiographie élective n'ait pas été réalisée chez les individus asymptomatiques. L'êtude de grandes familles pourrait fournir des informations importantes sur la fréquence de l'AI chez les individus à risque et le mode de transmission de l'HSA/AI familial. Méthodes: Nous avons revu les études de cas de HSA où au moins 4 membres d'une fratrie étaient atteints et où au moins un membre de la fratrie a subi une angiographie élective. Nous avons relevé l'âge de début, les manifestations cliniques, la présence d'hypertension, les observations angiographiques et l'évolution des patients. Un individu était considéré comme "atteint" s'il avait une HSA ou si un AI étaịt détecté à l'angiographie élective et "non atteint" s'il était asymptomatique et son angiogramme était négatif. Résultats: Sept études de cas comprenant 52 individus ( 26 hommes et 26 femmes) rencontraient ces critères d'inclusion. Les fratries variaient de 6 à 13 membres. La plupart des individus étaient asymptomatiques (32 sur 52, soit $61 \%), 18(35 \%)$ avaient une HSA et $2(4 \%)$ avaient des symptômes focaux sans HSA. L'angiographie élective faite chez 34 individus a montré un AI chez 11 (32\%) et s'est avérée négative chez 23 (68\%). La proportion d'individus atteints (HSA ou Al) était de 56\%. Conclusions: Dans ces fratries, l'angiographie a mis en évidence un $\mathrm{AI}$ chez près du tiers des individus asymptomatiques à risque. Le mode de transmission de l'HSA/AI familial était compatible avec une hérédité autosomale dominante dans ces fratries, bien que d'autres facteurs pourraient également être en cause.

Can. J. Neurol. Sci. 1995; 22: 121-125

The most common cause of a subarachnoid hemorrhage (SAH) is rupture of a saccular intracranial aneurysm (IA). The familial aggregation of SAH has been well described in the literature, with numerous case reports of families with two or more affected individuals. ${ }^{\text {i-4 }}$ Most of these reports have concentrated on describing only patients who have had a SAH. In many cases clinically asymptomatic individuals have not been studied with cerebral angiography, therefore the true incidence of IAs in these families has not been determined.

There are a few case series in which extended sibships have been studied in detail with angiography. ${ }^{5-7}$ By closely examining pooled data from such sibships, it may be possible to address two important issues; 1) the risk of occurrence of IA in sibships with familial SAH, and 2) the genetic mode of inheritance for IA. Such data can then be used to develop guidelines for the

From the Division of Neurology, Department of Medicine, Duke University Medical Center, Stroke Acute Care Unit, Duke Hospital (M.J.A.); Department of Neurobiology (A.D.R.), Division of Neurology (A.Q.,C.G.), Department of Medicine: Division of Neurosurgery, Department of Surgery (A.F.). Duke University Medical Center. Durham, North Carolina, USA.

RECEIVED AUGUST 16, 1994. ACCEPTED IN FINAL, FORM OCTOBER 31, 1994.

Reprint requests to: Mark J. Alberts, M.D., P.O. Box 3392, Duke University Medical Center, Durham, NC 27710 USA 
screening of asymptomatic individuals in families with SAH, and for studying the genetics of IA and SAH.

\section{METHODS}

We conducted a retrospective literature review using computerized library databases as well as published references and textbooks. All published reports of familial SAH or IA in English were reviewed. From this pool we ascertained those reports that had sibships of at least 4 individuals in which at least one asymptomatic individual was studied with intra-arterial cerebral angiography, and in which clinical and/or angiographic data was available from at least $50 \%$ of the individuals in the sibship (including the index case). Studies using intravenous digital subtraction angiography for screening were not included. We excluded sibships with fewer than four siblings, and sibships with insufficient clinical data to support the diagnosis of SAH, since they might skew subsequent statistical analyses. We also excluded reports of families with a known inherited condition (i.e., Ehlers-Danlos syndrome, polycystic kidney disease) that could cause familial IA or SAH.

Data were collected on clinical symptomatology, age of onset (if the patient had a SAH), age of angiography, and outcome. Patients were considered symptomatic for SAH if they had sudden onset of a severe headache accompanied by photophobia, nuchal rigidity, nausea/vomiting, or loss of consciousness. In all instances the diagnosis of SAH was confirmed by other findings such as bloody spinal fluid, cerebral angiography, or an autopsy. Patients without the above symptoms or without bloody spinal fluid who had other focal neurologic findings (i.e., cranial nerve palsies) due to an unruptured IA were classified as symptomatic/ focal. Individuals with only paroxysmal headaches, generalized weakness, or dizziness were not considered to be symptomatic. Cases of suspected SAH or IA without unequivocal clinical, radiologic, or autopsy confirmation were excluded.

The classifications of "affected" and "unaffected" were used for the genetic analyses. Patients were classified as "affected" if they had unequivocal clinical, radiologic, or pathologic evidence of an SAH or IA. For individuals undergoing elective angiography, an unequivocal cerebral aneurysm had to be seen for the study to be classified as positive (i.e., affected).
Infundibular widening was not sufficient for an individual to be classified as affected. Patients were defined as "unaffected" if they had not experienced a SAH and a cerebral angiogram or autopsy did not show an IA. Clinically asymptomatic individuals who were not studied with angiography were classified as "no data".

Individuals were classified as having hypertension (HTN) if the report stated a clear prior history. Since treatments for HTN were rarely noted, they are not included in our analyses. Individuals with a recorded blood pressure less than or equal to $140 / 90$, or who were noted specifically to not have a history of HTN, were classified as "no HTN". Patients found to have slightly elevated blood pressures (i.e., > 140/90 but $<160 / 95$ ) in the peri-stroke period without any other history of HTN were classified as "possible HTN". In most cases, no data were available on other risk factors such as smoking status and HLA antigens, therefore these factors were not included in our analysis.

\section{RESUlts}

There were seven case series (families) in the literature that met our inclusion criteria. ${ }^{6-12}$ These reports contained data on 52 patients, 26 men and 26 women. There were 29 affecteds and 23 unaffecteds. The mean age of the affecteds was 35.5 years, compared to a mean age of 35.8 years for the unaffecteds. Age data were not available from 11 individuals. A breakdown of clinical status by age and sex is in Table 1. Age-of-onset analysis showed a peak in the 30 s for patients with symptomatic SAH and individuals found to have an asymptomatic IA by angiography (Figure). The age-of-onset for SAH ranged from 22 to 59 years.

Eighteen of the 52 individuals $(35 \%)$ had a SAH, $32(61 \%)$ were asymptomatic, and $2(4 \%)$ were symptomatic/focal but did not have a SAH. Thirty-four patients without SAH (32 asymptomatic and 2 symptomatic/focal) underwent angiography. Eleven (32\%) were positive for IA, and $23(68 \%)$ were negative for IA (see Table 2). The mean ages of the individuals with positive angiograms was 37 years, compared to a mean age of 35.8 years in individuals with negative angiograms. The youngest individual with a positive angiogram was 21 years of age. Both patients classified as symptomatic/focal (but without an SAH) were found to have an IA on angiography.

Table 1: Demographic data and clinical status.

\begin{tabular}{|c|c|c|c|c|c|}
\hline Total subjects & 18 & 11 & 29 & 23 & 52 \\
\hline Males & 10 & 3 & 13 & 13 & 26 \\
\hline Females & 8 & 8 & 16 & 10 & 26 \\
\hline Age range (yrs)* & $21-59$ & $22-53$ & $21-59$ & $20-53$ & \\
\hline
\end{tabular}

*Age data was unavailable for 11 patients, 2 affected and 9 unaffected. Numbers in ( ) are standard deviations.

'SAH, subarachnoid hemorrhage

${ }^{2} \mathrm{~A}$, intracranial aneurysm

${ }^{3}$ affecteds include SAH and IA cases 
Table 2: Data on asymptomatic individuals who underwent elective angiography.

\begin{tabular}{llll}
\hline & $\begin{array}{l}\text { + angiogram } \\
\text { number }(\%)\end{array}$ & $\begin{array}{l}\text { - angiogram } \\
\text { number }(\%)\end{array}$ & Total \\
\hline No. subjects & $11(32)$ & $23(68)$ & 34 \\
Male' $^{\prime}$ & $3(19)$ & $13(81)$ & 16 \\
Female' $^{\prime}$ & $8(44)$ & $10(56)$ & 18 \\
Mean age $^{*}$ & 37.0 & 35.8 & 36.3 \\
\hline
\end{tabular}

'Angiogram results did not differ significantly by sex ( $p=0.11$ by Chisquare test)

* Age data was not available for 10 patients, 9 with a negative angiogram and one with a positive angiogram

The IAs ranged in size from $5 \mathrm{~mm}$ to $30 \mathrm{~mm}$ and multiple IAs were found in six patients, two of whom were asymptomatic. In one case the angiogram showed a small vestigial aneurysm of the right posterior communicating artery at age $35 .^{9}$ The patient had a SAH at age 41 , at which time a repeat angiogram showed a left posterior communicating artery aneurysm. The small vestigial aneurysm was unchanged. Two patients developed transient cortical blindness post-angiography with complete resolution of symptoms within 24 hours.

The sibships ranged in size from 6 to 13 siblings. In the smallest sibship there was clinical and angiographic data on 5 of 6 individuals, while such data was available on 12 of 13 individuals in the largest sibship (see Table 3). Clinical data or angiograms were not available or performed on 14 individuals from all of the sibships (ranging from 1 to 4 individuals per sibship), all of whom were apparently asymptomatic for SAH and IA. Among the parents of the sibships, SAH was documented or suspected in 4 parents ( 2 mothers and 2 fathers). In one family a father died of a cerebral infarction. He had complained of frequent headaches, but post-mortem examination did not reveal a SAH or any IAs.

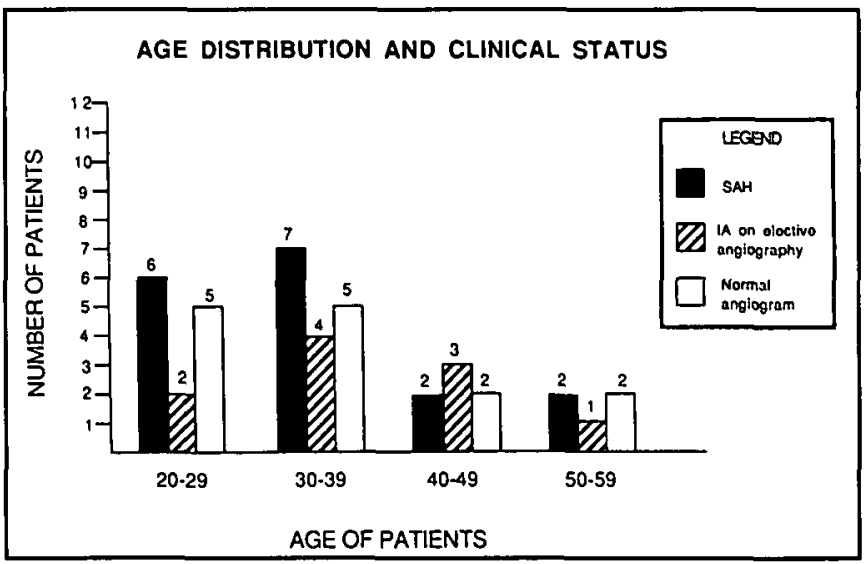

Figure: This bar graph shows the age distribution and clinical status for the 41 individuals with age data. Age data were not available for II individuals, 2 affected and 9 unaffected.

Detailed parental information was not reported for two families.

When data were summed over all subships, the rate of affecteds was $56 \%$. The maximum and minimum affected rates were calculated by assuming that individuals without data were either all affected or all normal, respectively. This calculation yielded a maximum affected rate of $65 \%$ and a minimum affected rate of $44 \%$ when data were pooled for all of the sibships (see Table 3 ).

The genetic study of such large sibships can be influenced by ascertainment bias. Since the proband of each sibship was ascertained because they had a SAH, we re-analyzed the sibships after eliminating each proband. This analysis showed an overall affected rate of $49 \%$, which is consistent with an autosomal dominant trait segregating in this series of sibships.

Hypertension was relatively uncommon in this series of sibships and was not a powerful risk factor for SAH or IA. Definite or possible HTN was present in 4 of $14(29 \%)$ SAH patients, while $10(71 \%)$ SAH patients were normotensive. Among individuals with IAs found by elective angiography, HTN (definite or possible) was present in one of eight cases for which data was available (see Table 4).

Table 3: Clinical status and sibship size.

\begin{tabular}{|c|c|c|c|c|c|c|c|}
\hline Edelsohn ${ }^{10}$ & 10 & 4 & 4 & 2 & 50 & 60 & 40 \\
\hline Fox ${ }^{6}$ & 13 & 7 & 5 & 1 & 58 & 62 & 54 \\
\hline Halal ${ }^{9}$ & 10 & 4 & 2 & 4 & 67 & 80 & 40 \\
\hline Patrick $^{8}$ & 11 & 5 & 3 & 3 & 63 & 73 & 45 \\
\hline Leblanc $^{12}$ & 6 & 2 & 3 & 1 & 40 & 50 & 33 \\
\hline Totals & 66 & 29 & 23 & 14 & 56 & 65 & 44 \\
\hline $\begin{array}{l}\text { Totals excluding } \\
\text { proband }{ }^{* *}\end{array}$ & 59 & 22 & 23 & & 49 & 61 & 37 \\
\hline
\end{tabular}

" Affecteds were defined as having a SAH or IA

* \% Probands were excluded to correct for potential ascertainment bias. See text for details. 
Table 4: Hypertension and clinical status.

\begin{tabular}{lllll}
\hline $\begin{array}{l}\text { Presence of } \\
\text { HTN }\end{array}$ & \multicolumn{5}{c}{ Clinical findings } \\
& Negative & IA $^{\mathbf{2}}$ & SAH $^{\mathbf{3}}$ & Total \\
\hline HTN & 1 & 1 & 2 & 4 \\
No HTN & 10 & 7 & 10 & 27 \\
Possible HTN & 1 & 0 & 2 & 3 \\
No data & 11 & 3 & 4 & 18 \\
Total & 23 & 11 & 18 & 52 \\
\hline
\end{tabular}

'HTN, hypertension

${ }^{2} \mathrm{IA}$,intracranial aneurysm

${ }^{3} \mathrm{SAH}$, subarachnoid hemorrhage

Patients with a SAH had a mortality of $33 \%$ (6 of 18 ). Surgical clipping was recommended for 10 cases of IAs discovered by elective angiography (there was no information about one case). All 10 patients underwent surgical clipping, one of which died in the post-operative period. On patient developed a transient hemiparesis postoperatively that completely resolved, one experienced a transient aphasia and seizures, and one had a permanent hemiparesis related to ligation of the common carotid artery.

\section{DisCuSSION}

This study found that for asymptomatic individuals in a large sibship with SAH, the risk to siblings of harboring an IA detected by angiography was $32 \%$. This represents at least a four-fold increased risk when compared to the $0.5 \%$ to $7.2 \%$ incidence of IAs found in various autopsy studies. ${ }^{4.13-15}$ A retrospective study in Finland found that at least $10 \%$ of SAH patients had a positive family history of $\mathrm{SAH} .{ }^{16}$ This finding was confirmed by a prospective study using magnetic resonance angiography (MRA) to screen for IAs in family members of SAH patients. ${ }^{17}$ This $10 \%$ prevalence of famial IAs in that population may be an underestimate, since not all at-risk family members were studied. By comparison, the increased rate of asymptomatic IAs in the sibships from our study is most likely due to several factors, including publication and ascertainment bias, along with the increased sensitivity of conventional angiography compared to MRA for detecting IAs.

There is growing evidence that some cases of SAH and IA are due to genetic factors. ${ }^{3}$ In many families with $\mathrm{SAH}$, the mode of inheritance is unclear, due mostly to small kindreds that have not been well ascertained or fully investigated. Autosomal dominant and multifactorial patterns have been postulated, yet none has been proven. ${ }^{2}$ The compilation of case series presented in this paper provide evidence that some cases of SAH/IA display a strong familial aggregation that is greater than would be expected based on population-based studies. For example, a questionnaire-based study by Norrgard et al. ${ }^{4}$ found a $6.7 \%$ rate of familial IAs. However, this type of study has a high probability of underestimating the number of asymptomatic affecteds due to incomplete ascertainment and lack of systematic diagnostic testing.

We found a substantially earlier mean age for individuals with IA or SAH, compared to previous studies. For patients with
SAH the mean age was 34.6 years, and individuals found to have an IA on elective angiograms had a mean age of 37 years. A Finnish study found familial SAH patients to be slightly younger (mean age 44 years, males; 49 years, females) than non-familial SAH cases ( 47 years, males; 52 years, females.) ${ }^{16}$ Other studies have reported mean ages ranging from 39 to 42.3 years for familial IA compared to an age range of 50-54 years for non-familial IAs ${ }^{3,18,19}$ These findings may be explained partially by ascertainment effects, since our study had many asymptomatic individuals who were motivated to undergo elective angiography at a young age. By ascertaining large sibships with many living individuals we could have excluded older sibships with many deceased members. However, we did not find any examples of large older sibships in the literature. The detection of a strong familial pattern has been observed in early-onset kindreds with other complex genetic diseases such as Alzheimer's disease and certain types of cancer. ${ }^{20.21}$ This may be due primarily to genetic factors, although ascertainment bias could be a contributing influence

When evaluating the use of MRA or conventional angiography as screening tools for IAs, it is important to consider the dynamic nature of IA formation. There are several cases in the literature where an angiogram was negative and the patient had a SAH several yeas later due to a ruptured IA.4.9.22 This finding may be explained in some cases by the ability of IAs to appear or enlarge withing the span of a few years. ${ }^{23-25}$ Other factors such as technical limitations of the angiogram (i.e., failing to image all of the vessels, suboptimal projection angles, misreads) might contribute to such cases. Therefore, a negative angiogram does not rule out the possibility of IA formation several years later. A related explanation may be that in some cases the IA gene(s) does not become fully penetrant until later in life.

What are the implications of this study? Determining the risk of IA formation for asymptomatic individuals in families with $\mathrm{SAH}$ is important for providing genetic counseling and advice about undergoing further study. ${ }^{2}$ It has been argued that angiographic screening is not beneficial in individuals less than 30 years of age. ${ }^{2}$ In our data set, $6(33 \%)$ of the $18 \mathrm{SAH}$ patients and $2(18 \%)$ of the 11 individuals with IAs on elective angiography (and age data) were less than 30 years of age. Studies by Ronkainen et al. ${ }^{16.17}$ found that $10 \%-12 \%$ of asymptomatic family members may have IAs. This implies a large number of individuals are at-risk for developing a SAH. Since a substantial number of individuals with IAs become symptomatic prior to age 30, screening (with MRA) may be appropriate at a younger age for individuals with a "strong" family history of SAH.

We would define a "strong" family history as follows: 1) an individual with an affected parent and one or more affected siblings, 2) an individual with two or more affected siblings, 3) an individual with an affected parent and child, 4) an individual with an affected parent and two or more affected first-degree relatives (of the affected parent). In all cases, individuals with a family history of SAH or IA who are having focal symptoms suggestive of an IA should undergo angiography. These recommendations may be modified for families with a known inherited disorders (i.e., polycystic kidney disease) that can increase the risk of IA formation. 26

The clinical and radiological screening of asymptomatic individuals for IAs should be performed by a coordinated and experienced team, consisting of a neurologist or neurosurgeon, 
neuroradiologist, and geneticist. Detailed demographic, medical, and family history data should be obtained, along with blood samples for future DNA testing and genetic studies. A prospective database of all such patients should be created so that long term results of efficacy and complication rates can be collected.

There are some potential limitations of our study. This was a retrospective study using previously published data from several sources, which could introduce some ascertainment bias. There was likely to be some bias in favor of publishing large sibships with several affecteds. However, we determined at the outset that we would only review cases with large, well studied sibships, independent of the number of affecteds found. By applying these criteria prospectively, we did not select only for sibships with many known affecteds. It is important to note that more than half (34 of 52 siblings with data, and 34 of 66 total siblings) of the individuals in the combined sibships underwent elective angiography, and in three sibships $50 \%$ or more of the individuals were unaffected. This argues against a marked bias in favor of publishing only sibships with large numbers of affecteds. Our study is the first to analyze pooled genetic data from large published sibships that specifically included individuals who were studied by elective angiography. By specifically including large sibships in which individuals underwent elective cerebral angiography, we attempted to reduce potential ascertainment biases. Even considering these ascertainment factors, these data still suggest the existence of a subset of families with a high prevalence of SAHs and IAs.

We excluded families with a known inherited disorder such as polycystic kidney disease and Ehler-Danlos type IV, since such pedigrees would have significantly biased our results. Even when such diseases are excluded, it is still possible that familial $\mathrm{SAH}$ and IA will be a genetically heterogeneous group of disorders. Other clinical studies have reported significant similarities for IA site and age of detection among sets of siblings. ${ }^{19}$ These findings suggest that a large prospective study is warranted to further characterize the familial clustering of SAH and IA.

In summary, members of sibships that contain several patients with SAH or IA may have a substantial risk of having an asymptomatic IA, even at a relatively young age. Although these families represent a subset of all SAH cases, serious consideration should be given to screening such high-risk individuals with MRA and/or elective angiography to prevent the catastrophic consequences of a SAH. Because of the dynamic nature of IA formation and growth, serial screenings may be required in selected cases.

\section{ACKNOWLEDGEMENTS}

The authors thank Marcy Speer, $\mathrm{PhD}$ for her expert assistance in reviewing the manuscript and providing helpful suggestions, and Ms. Tina Brantley for her excellent secretarial support. This work was supported in part by the following grants: an American Heart Association Grant-in-Aid and an Established Investigator award to Dr. Alberts; an American Heart Association Medical Student Scholarship to Ms. Quinones; a Canadian Heart and Stroke Foundation Fellowship Grant to Dr. Graffagnino.

\section{REFERENCES}

I. Elshunnar K, Whittle I. Familial intracranial aneurysms: report of five families. Br J Neurosurg 1990; 4: 181-186.
2. terBerg H, Dippel D, Limburg M, Schievink W, van Gijn J. Familial intracranial aneurysms: a review. Stroke 1992; 23: 1024-1030.

3. Lozano A, Leblanc R. Familial intracranial aneurysms. J Neurosurg 1987; 66: 522-528.

4. Norrgard O, Angquist K, Fodstad H, Forsell A, Lindberg M. Intracranial aneurysms and heredity. Neurosurgery 1987; 20: 236-239.

5. Bannerman R, Ingall G, Graf $C$. The familial occurrence of intracranial aneurysms. Neurology 1970; 20: 283-292.

6. Fox J. Familial intracranial aneurysms. J Neurosurg 1980; 57: 416-417.

7. Mellgard $P$, Ljunggren B, Brandt L, Johnson U, Holtas S. HLAtyping in a family with six intracranial aneurysms. Br J Neurosurg 1989; 3: 479-486.

8. Patrick D, Appleby A. Familial intracranial aneurysm and infundibular widening. Neuroradiology 1983; 25: 329-334.

9. Halal F, Mohr G, Toussi T, Martinez N. Intracranial aneurysms: a report of a large pedigree. Am J Med Genetic 1983; 15: 89-95.

10. Edelsohn L, Caplan L, Rosenbaum A. Familial aneurysms and infundibular widening. Neurology 1972; 22: 1056-1060.

11. Evans T, Venning M, Strang F, Donnai D. Dominant inheritance of intracranial berry aneurysm. Br Med J 1981; 283: 824-825.

12. Leblanc R, Lozano A, van der Rest M, Guttmann D. Absence of collagen deficiency in familial cerebral aneurysms. J Neurosurg 1989; 70: 837-840.

13. Sahs A, Perret G, Locksley H, Nishioka H, Skultety F. Preliminary remarks on subarachnoid hemorrhage. J Neurosurg 1966; 24: 782-788.

14. Richardson J, Hyland H. Intracranial aneurysms. A clinical and pathological study of subarachnoid and intracerebral hemorrhage caused by berry aneurysms. Medicine 1941; 20: 1-83.

15. Chason J, Hindman W. Berry aneurysms of the circle of Willis: results of a planned autopsy study. Neurology 1958; 8: 41-44.

16. Ronkainen A, Hernesniemi J, Ryynanen M. Familial subarachnoid hemorrhage in East Finland, 1977-1990. Neurosurgery 1993; 33: 787-797.

17. Ronkainen A, Hernesniemi J, Ryynanen M, Puranen $M$, Kuivaniemi $H$. A ten percent prevalence of asymptomatic familial intracranial aneurysms: preliminary report on 110 magnetic resonance angiography studies in members of 21 Finnish familial intracranial aneurysm families. Neurosurgery 1994; 35: 208-213

18. Locksley H. Natural history of subarachnoid hemorrhage, intracranial aneurysms and arteriovenous malformations. In: Sahs A, Perret G, Locksley $H$, et al., eds. Intracranial Aneurysms and Subarachnoid Hemorrhage: A Cooperative Study. Philadelphia: JB Lippincott, 1969: 37-108.

19. Andrews R. Intracranial aneurysms: characteristics of aneurysms in siblings. N Engl J Med 1977; 297: 115.

20. Goate A, Chartier-Harlin C, Mullan M, et al. Segregation of a missense mutation in the amyloid precursor protein gene with familial Alzheimer's disease. Nature 1991; 349: 704-706.

21. Peltomaki P, Aaltonen L, Sistonen P, et al. Genetic mapping of a locus predisposing to human colorectal cancer. Science 1993; 260: 810-812.

22. Schievink W, Limburg M, Dreissen J, Peeters F, ter Berg H. Screening for unruptured familial intracranial aneurysms: subarachnoid hemorrhage 2 years after angiography negative for aneurysms. Neurosurgery $1991 ; 29: 434-437$.

23. Sarwar M, Batnitzky S, Schechter M, Liebeskind A, Zimmer A. Growing intracranial aneurysms. Radiology 1976; 120: 603607.

24. Allcock J, Canham P. Angiographic study of the growth of intracranial aneurysms. J Neurosurg 1976; 45: 617-621.

25. Sekhar L, Heros R. Origin, growth and rupture of saccular aneurysms: a review. Neurosurgery 1981; 8: 248-260.

26. Lozano A, Leblanc R. Cerebral aneurysms and polycystic kidney disease: a critical review. Can J Neurol Sci 1992; 19: 222-227. 